\title{
Ecological versatility and its importance for the distribution and abundance of coral reef wrasses
}

\author{
Charlotte Berkström ${ }^{1,2, *}$, Geoffrey P. Jones ${ }^{1}$, Mark I. McCormick ${ }^{1}$, Maya Srinivasan ${ }^{1}$ \\ ${ }^{1}$ ARC Centre of Excellence for Coral Reef Studies, and School of Marine and Tropical Biology, James Cook University, \\ Townsville, Queensland 4811, Australia \\ ${ }^{2}$ Present address: Department of Systems Ecology, Stockholm University, 10691 Stockholm, Sweden
}

\begin{abstract}
Ecological versatility, the degree to which organisms fully exploit the available resources, is an important component of ecological and evolutionary theory. However, patterns and consequences of versatility in coral reef fish have received little attention. Using a comparative approach, this study tested the consequences of ecological versatility on the distribution and abundance of juvenile wrasses (family: Labridae) in Kimbe Bay, Papua New Guinea. Resource use was examined along 4 different resource axes (horizontal distribution or reef zone, vertical distribution or depth, microhabitat and diet). Stepwise multiple regressions were used to test for relationships between niche breadth and patterns of abundance and distribution. Most exhibited a degree of apparent specialisation on at least one resource, but none were specialised along all resource axes. In terms of juvenile diet, the majority of species exhibited a high reliance on harpacticoid copepods. Microhabitat specialisation was associated with low local abundance and narrow distribution among depth zones. However, diet and macrohabitat specialisation were poor predictors of local abundance, and no relationships between local abundance, and local and regional distribution were observed. We conclude that the relationship between versatility and abundance/distribution is dependent on the resource in question. A greater understanding of the degree of ecological versatility in relation to different resources is necessary to predict how reef fishes will respond to escalating human impacts on coral reefs.
\end{abstract}

KEY WORDS: Coral reef fish $\cdot$ Depth distribution $\cdot$ Diet $\cdot$ Habitat use $\cdot$ Harpacticoid copepods · Specialisation · Labridae

\section{INTRODUCTION}

The range of resources used by organisms has important implications for ecological patterns at both population and community levels (Ross 1986). The different abilities of species to exploit resources and perform in various environments are often important in limiting their abundance and distribution (Schoener 1974, Brown 1984, Hanski et al. 1993, McPeek 1996, Hughes 2000). Knowledge of species resource requirements can provide insights into how populations are regulated and how ecological communities are structured. Ecological versatility has been defined as 'the degree to which organisms can fully exploit the available resources in their local environment' (MacNally 1995, p. 19). Versatile species are those that exploit a large number of resources and are usually referred to as generalists (Pianka 1974, Futuyma \& Moreno 1988, MacNally 1995), while specialists exploit only a narrow range of resources (Futuyma \& Moreno 1988, MacNally 1995, Timms \& Read 1999). As extreme specialists and generalists are likely to represent opposite ends of a resource-use continuum (Rachlin et al. 1989, Morris 1996), the term versatility was coined to encompass the whole spectrum (MacNally 1995). The consequences of ecological versatility 
are receiving increasing attention due to the high extinction risk associated with ecological specialisation in a changing environment (Hawkins et al. 2000, Harcourt et al. 2002, Davies et al. 2004, Hobbs et al. 2011).

Ecological versatility has been suggested to play a major role in determining local patterns of distribution and abundance. This was formalised by Brown (1984), who proposed that species with broad environmental tolerances and resource generalists will have the capacity to achieve high local densities and be able to survive in more places and hence over larger areas. In contrast, species that have narrow environmental tolerances, which are able to use only a narrow range of resources (specialists), will be unable to attain either high local densities or extensive distributions (Brown 1984). In a similar vein, there may be a relationship between ecological versatility, and regional and geographic abundance and distribution. Species with wide geographic ranges have been shown to be more abundant than species with narrow distributions (Hanski 1982, Bock \& Ricklefs 1983, Gaston 1990, Gaston 1994, Hanski \& Gyllenberg 1997). These general ecological patterns have been documented over a broad diversity of taxa, in different biogeographic regions and in a variety of habitats (Gaston \& Blackburn 1996).

While many studies provide support for Brown's ecological specialisation hypothesis (e.g. Gaston 1988, Inkinen 1994, Pyron 1999, Hughes 2000, Bean et al. 2002), support is not universal (Fowler \& Lawton 1982, e.g. Hanski et al. 1993, Gregory \& Gaston 2000, Gaston \& Spicer 2001). Few explicit tests have been carried out and the vast majority have focused on terrestrial organisms (Gaston et al. 1997, Gaston \& Spicer 2001). In addition, as animals use a range of resources, it is critical to know the level of specialisation on different resources. Resource utilisation in animals can be viewed in a hierarchical framework, from the use of 'macrohabitats' in which an individual spends most of its time, to the use of 'microhabitats' within an individual's home range, to the selection of particular elements (food items) from different microhabitats (Manly et al. 1993). A full evaluation of the effects of specialisation on distribution and abundance requires niche breadth to be quantified along different resource axes.

For coral reef fishes, patterns of ecological versatility and their consequences for distribution and abundance have received relatively little attention (but see Munday \& Jones 1998, Bean et al. 2002, Jones et al. 2002, Pratchett et al. 2008, Hobbs et al. 2010). According to Ross (1986), many fishes seem to be highly versatile and opportunistic, displaying high overlap in resource use. They have an extraordinary potential for trophic niche expansion, exploitation of highly fluctuating and diverse trophic resources, and for being facultative rather than obligate specialists (Liem 1984, 1990). However, a large number of coral reef fishes show high degrees of apparent specialisation, being associated with either 1 biotic microhabitat, 1 prey group or 1 symbiotic partner (Fautin \& Allen 1992, Munday 2004, Pratchett 2005). This suggests that for coral reef fishes, specialisation might be more pronounced and important for abundance and distribution than previously thought. Furthermore, studies have shown that specialised coral reef fish species display low local abundances, in accordance with Brown's theory (Munday 2000, Bean et al. 2002, Gardiner \& Jones 2005). However, recent evidence suggests that coral reef fish species with small geographic ranges around isolated islands can have high local abundances (De Martini \& Friedlander 2004, Hobbs et al. 2011).

Recent studies have shown declines in fish communities associated with degrading coral reef habitats (Jones et al. 2004, Wilson et al. 2006, Wilson et al. 2009), especially species specialised on live coral (Pratchett et al. 2006, Graham 2007). The community-wide response to degradation and variation in resource availability will fundamentally depend on the versatility of the constituent species. Gardiner \& Jones (2005) suggested that communities composed of a high proportion of resource specialists that are specialised on a particular habitat type that is undergoing degradation will be particularly vulnerable. However, species are not necessarily specialised on all resources, and not all resources are necessarily in decline. Determination of the degree of versatility of reef fishes in relation to different resources is needed to understand the effect of coral reef degradation on their abundance and distribution.

The overall aim of this study was to examine the effects of ecological versatility on the abundance and distribution of a group of coral reef wrasses from the family Labridae. The family Labridae encompasses species that range from those with highly specialised diets to highly opportunistic carnivores. They utilise a number of different habitats and are found at a variety of different depths (Green 1996, Myers 1999, Allen et al. 2003). They are also an important component of the ichthyofauna on coral reefs throughout the world, being the second most species-rich family on the Great Barrier Reef, Australia (Thresher 1991, Randall et al. 1997). To avoid the complication of ontogenetic shifts in ecology, the present study focuses on the juvenile life stage. 
The specific goals were to (1) examine patterns of apparent specialisation or niche breadth along 4 different resource axes (horizontal distribution or reef zone, vertical distribution or depth, microhabitat and diet); (2) test the hypotheses derived from Brown's (1984) theory that greater niche breadth for any one resource is associated with (i) a greater local abundance, (ii) a greater local distribution among habitats and (iii) a greater geographic range; and (3) test if there is a relationship between local abundance and geographic range, i.e. species with wide geographic ranges have high local abundances.

\section{MATERIALS AND METHODS}

\section{Study site and species}

The study was carried out at Kimbe Bay, West New Britain Province, Papua New Guinea (530' S, $\left.150^{\circ} 05^{\prime} \mathrm{E}\right)$. Kimbe Bay has a dense network of platform reefs ranging in size from tens to hundreds of metres in diameter, and several small continental islands surrounded by well-developed fringing reefs (Munday 2002). The reefs used in this study are located close to shore, extending down to depths of $>200 \mathrm{~m}$ and breaking the surface at low tide. The reefs can be clearly split into several reef zones: the reef flat, the windward reef crest and slope/ wall, and the leeward reef slope. Eleven species from the family Labridae were chosen for this study: Diproctacanthus xanthurus, Halichoeres argus, $H$. chloropterus, H. hortulanus, H. melanurus, H. purpurescens, Labrichthys unilineatus, Labroides dimidiatus, Oxycheilinus celebicus, Paracheilinus filamentosus and Thalassoma lunare. These species were chosen because they were expected to encompass a wide range of patterns in resource use and to differ in their local abundances. Niche breadth data for these species were collected during March and April 2002 on 9 reefs (Lady Di, Limuka, Rakaru Diri, Hanging Gardens, Garbuna, Reef 1, Reef 2, Donna's and Vanessa's, Fig. 1). As part of another study examining seasonal patterns of recruitment and densities of new recruits of the same species, juvenile fish were surveyed every 4 to $8 \mathrm{wk}$ between December 1998 and April 2001 at different depths on 6 reefs (Gava Gava, Limuka, Luba Luba, Madaro, Mahonia Front and Walindi Front; Srinivasan \& Jones 2006).

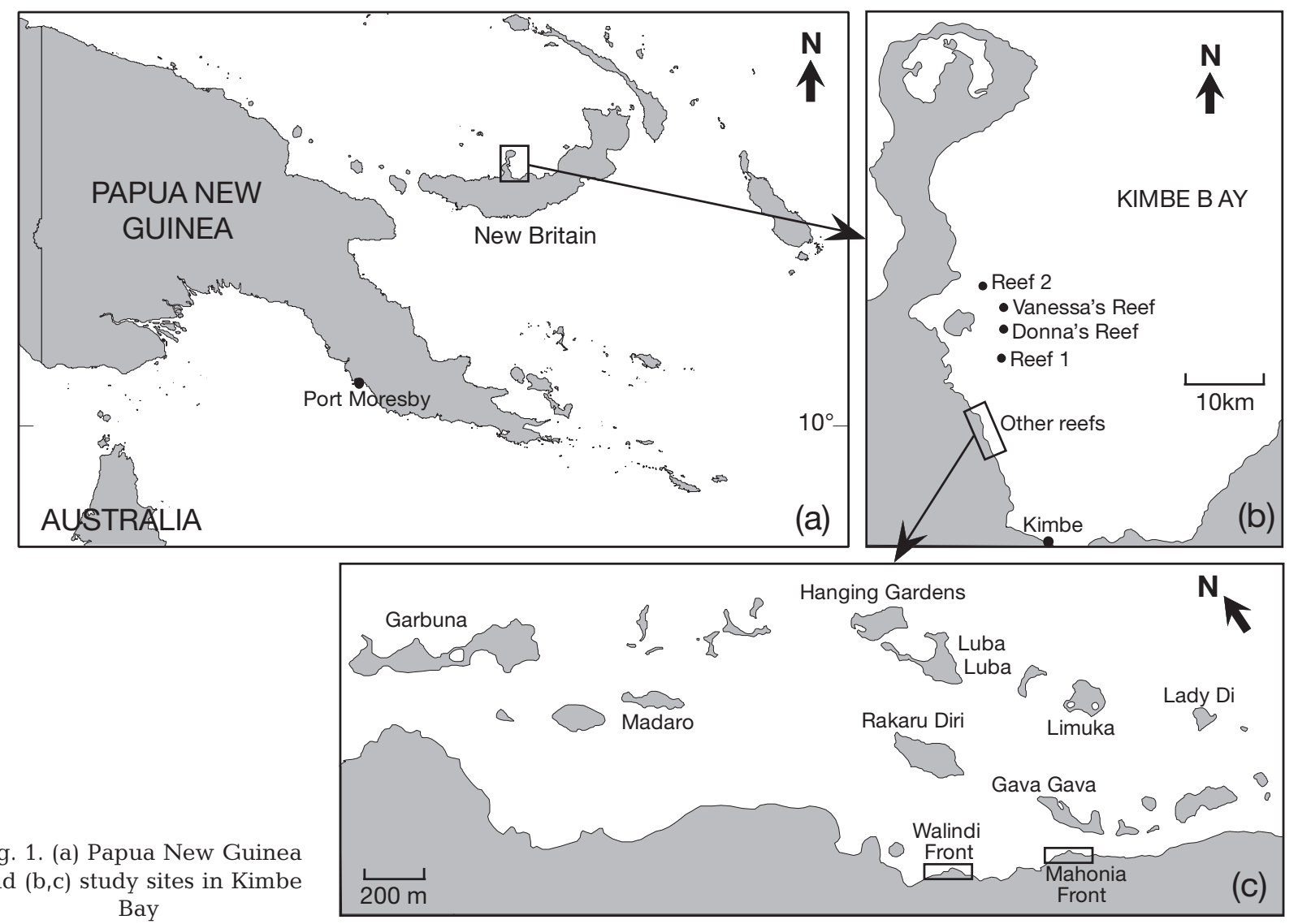




\section{Local distribution among depth zones, reef zones and microhabitats}

Niche breadth can be measured by observing the distribution of individual organisms within a set of resource states or resource categories (Krebs 1999). The specialist's resource range should be included in that of the generalist's as this makes the judgment of the relative degree of specialisation more reliable (McNaughton \& Wolf 1970, Futuyma \& Moreno 1988). To observe the distribution of individual wrasses within large- and small-scale habitat categories, transects were randomly placed on the windward (2 transects) and leeward (2 transects) sides of 9 different reefs in Kimbe Bay, a total of 36 transects. Depth, reef zone and microhabitat were recorded for each juvenile found within the $20 \mathrm{~m}$ wide transect. To cover a large depth and habitat range, transects were placed at $20 \mathrm{~m}$ depth and run up the slope or wall, over the crest and across the reef flat of each reef sampled. Transects ended where the reef broke the surface and varied in length, from 18 to $48.5 \mathrm{~m}$ long. Transects were simply a way of making sure that similar amounts of effort were allocated to the whole depth range available for the study. Each transect

Table 1. Depth and reef zones, microhabitats and food items used for studying resource use in juveniles (juv.) from 11 wrasse species in Kimbe Bay, Papua New Guinea. All corals are hard corals except 'black coral' and 'soft coral'. par.: parasitic

\begin{tabular}{|c|c|c|c|}
\hline $\begin{array}{l}\text { Depth } \\
\text { zones (m) }\end{array}$ & Reef zones & Microhabitats & Food items \\
\hline $0.0-2.5$ & Back patch & Bare rock & Harpacticoid copepods \\
\hline $2.5-5.0$ & Back wall & Dead coral & Calanoid copepods \\
\hline $5.0-7.5$ & Back slope & Rubble & Cyclopoid copepods \\
\hline $7.5-10.0$ & Back crest & Sand & Parasitic copepods \\
\hline $10.0-12.5$ & Reef flat & Turf & Cirripedi (barnacle) larvae \\
\hline $12.5-15.0$ & Front crest & Macroalqae & Amphipods \\
\hline $15.0-17.5$ & Front slope & Sponge & Gnathid amphipod larvae (par.) \\
\hline \multirow[t]{16}{*}{$17.5-20.0$} & Front wall & Soft coral & Isopods \\
\hline & & Fire coral & Ostracods \\
\hline & & Black coral & Tanaeids \\
\hline & & Branching coral & Crabs (megalopa-stage) \\
\hline & & Bushy coral & Nauplii \\
\hline & & Corymbose coral & Bivalves (juv.) \\
\hline & & Digitate coral & Gastropods (juv.) \\
\hline & & Columnar coral & Polychaetes \\
\hline & & Tabular coral & Insects \\
\hline & & Encrusting coral & Diatoms (Coscinodiscus) \\
\hline & & Massive coral & Dinoflagelattes (Paradinium) \\
\hline & & Solitary coral & Forams (Globigerinida) \\
\hline & & & Protozoans \\
\hline & & & Coral polyps \\
\hline & & & Eggs/egg mass \\
\hline & & & Fish scales \\
\hline
\end{tabular}

was divided into 8 depth categories and 8 reef zone categories (Table 1). The local distribution of a species was described as the distribution across reef and depth zones on a single reef. Occurrence in a large number of reef zones denotes a broad horizontal distribution, while occurrence in a large number of depth zones denotes a broad vertical distribution. Microhabitats were divided into 19 microhabitat categories (Table 1), based on major non-living and living substrates. Live coral was divided according to growth form, as reef fishes are known to exhibit preferences for particular growth forms of coral (Gardiner \& Jones 2005, Bonin et al. 2011).

\section{Diet}

In order to estimate selectivity of food resources, 20 or more random juveniles of each species were collected from reefs around Kimbe Bay for gut content analyses. Juveniles were caught with a hand net after being anaesthetised with a 1:10 clove oil/ alcohol solution administered from a hand-held spray bottle. Following capture, fish were held on ice to stop any breakdown of tissue until placed in separate vials of $10 \%$ buffered seawater/ formalin solution. In the laboratory, guts were removed from the specimens under a stereomicroscope and their contents were sorted. Prey items were temporarily mounted on a slide with Grey and Wess mountant and were taxonomically identified to class and, if possible, order under high magnification. Prey items were divided into 23 categories, based on major prey groups from similar environments (e.g. pelagic, benthic or parasitic, Table 1). The number of different prey categories per gut and the percentage each prey category constituted per gut was recorded. Two coefficients (mean volumetric percentage, MVP, and percentage frequency of occurrence, $\mathrm{PFO}$ ) were calculated to determine the relative importance of prey items in the diet. The MVP of a prey is the sum of individual volumetric percentages for the food items divided by the number of specimens examined. The PFO is the number of stomachs containing a particular prey item as a percentage of the total num- 
ber of stomachs containing food. Unidentifiable prey items were not included as a prey category in the calculations of food selectivity coefficients, as most of the fish guts contained a high percentage of these items (often $>50 \%$ ). Including this category would have resulted in all labrid species having high niche overlap, i.e. all specialised on unidentifiable prey. We acknowledge, however, that actual niche overlap between species may vary from that estimated in this study, depending on whether unidentified items were the same or different between species.

\section{Niche breadth}

Niche breadths for depth, reef zone, microhabitat and diet of 11 species of wrasses were calculated using Levins' (1968) niche breadth formula. This measures the uniformity of distribution of individuals among the resource categories as:

$$
B=1 /\left(\Sigma p_{j}^{2}\right)
$$

where $B$ is Levins' measure of niche breadth and $p_{j}$ is the proportion of individuals found in or using resource state $j$. The range of $B$ is from 1 to $n$, where $n$ is the total number of resource categories. $B$ is minimal when all individuals occur in only 1 resource state (minimum niche breadth, maximum specialisation). To facilitate comparisons among species, Levins' niche breadth was standardised in accordance with Hurlbert (1978) using the formula:

$$
B_{A}=(B-1) /(n-1)
$$

where $B_{A}$ is Levins' standardised niche breadth, $B$ is Levins' measure of niche breadth and $n$ is the number of possible resource categories. The standardised niche breadth $\left(B_{A}\right)$ is expressed on a scale from 0 to 1 , where a value close to 0 represents a narrow niche breadth and high specialisation.

\section{Local abundance}

Local abundances for the 11 study species were estimated using depth-stratified visual transects. Four $50 \times 2 \mathrm{~m}$ transects were randomly placed at each of 4 depths $(0,2,6$ and $10 \mathrm{~m})$ on the windward sides and at $2 \mathrm{~m}$ on the leeward sides of 4 platform reefs (Gava Gava, Limuka, Luba Luba and Madaro) and at each of 3 depths $(0,2$ and $6 \mathrm{~m})$ on 2 areas of fringing reef (Mahonia Front and Walindi Front). All newly settled individuals within $1 \mathrm{~m}$ on each side of the $50 \mathrm{~m}$ transect tape were recorded. Juveniles were of a similar size range to those surveyed for niche breadth. Depths deeper than $2 \mathrm{~m}$ were not surveyed on the leeward sides of the reefs as the cover of hard substrata generally did not extend beyond 3 to $4 \mathrm{~m}$ depth on this side of the reef. This was also the case for depths beyond $6 \mathrm{~m}$ on the fringing reefs. As these surveys were part of a study examining seasonal patterns (Srinivasan \& Jones 2006), they were carried out a total of 20 times, every 4 to $8 \mathrm{wk}$, from December 1998 to April 2001, with a total of 108 transects surveyed each time.

Although niche breadth data and local abundance data were collected at different time periods, niche breadth data were collected less than 1 yr after the last of the abundance surveys, and it was assumed that the relative abundances of juveniles of the 11 wrasse species would not have changed significantly over this time. In addition, although there has been a gradual decline in coral cover on these reefs (Jones et al. 2004), patterns of microhabitat use of juvenile wrasses were assumed to have not changed significantly between the 2 time periods.

\section{Geographic range}

The geographic range of each species was assessed from the literature (Myers 1999, Froese \& Pauly 2002, Allen et al. 2003). Range size was calculated as the relative size of the biogeographic region in which each species is found, i.e. the area between the outermost limits of a species occurrence. A contour map for each species was constructed in a similar fashion to Allen et al. (1998) using occurrence data from Myers (1999), Froese \& Pauly (2002) and Allen et al. (2003). The size of each species' geographic range was estimated by digitising maps using Sigma Scan computer software.

\section{Data analyses}

Multiple stepwise regression was used to test for relationships between niche breadth and local abundance, local distribution (vertical and horizontal distribution) and geographic range, respectively. For local abundance and geographic range, all 4 niche dimensions (depth, reef zone, microhabitat and diet) were used as predictor variables. However, depth was omitted from the analysis involving local vertical distribution, and reef zone was omitted from the analysis involving local horizontal distribution, as these 2 sets of variables were not independent. 


\section{RESULTS}

\section{Local distribution among depth zones, reef zones and microhabitats}

Halichoeres argus displayed the narrowest depth range (0 to $2.5 \mathrm{~m}$ ), followed by $H$. hortulanus (0 to 5 m, Fig. 2). H. chloropterus, Labrichthys unilineatus and Thalassoma lunare were found between 0 and $15 \mathrm{~m}$, but were most abundant between 0 and $5 \mathrm{~m}$. Labroides dimidiatus and $H$. melanurus were found throughout the $20 \mathrm{~m}$ depth range, but were most frequently observed between 0 and $10 \mathrm{~m}$. Diproctacanthus xanthurus, $H$. purpurescens and Oxycheilinus celebicus were evenly spread throughout most depth zones. However, O. celebicus was rarely found in depths less than $5 \mathrm{~m}$. Paracheilinus filamentosus was found between 5 and $20 \mathrm{~m}$, displaying highest percent occurrence between 15 and 20 m (Fig. 2).

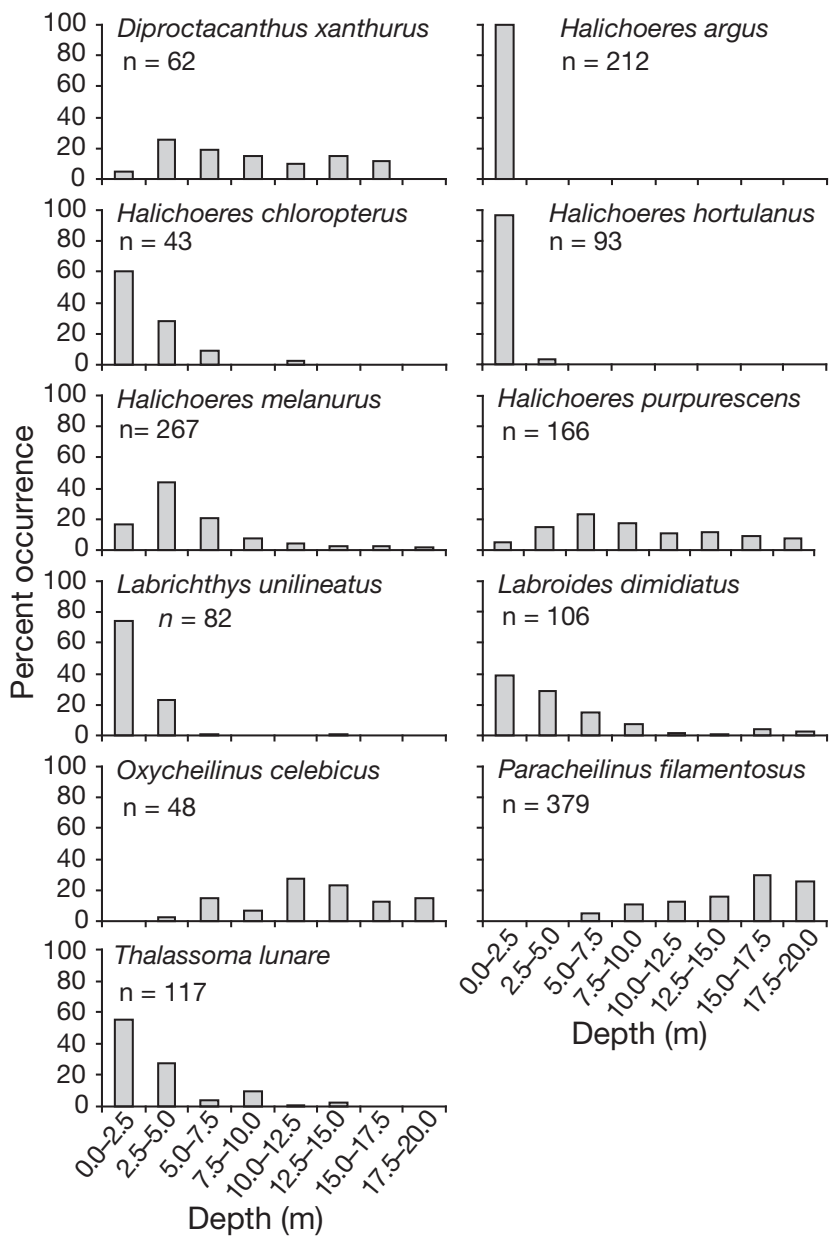

Fig. 2. Local vertical distributions of 11 species of juvenile wrasses on coral reefs in Kimbe Bay, Papua New Guinea, shown as the percent occurrence of individuals in each of the 8 depth zones
Substantial differences among species were found in the number of broad reef zones occupied. Two species (Halichoeres argus and $H$. hortulanus) were predominantly found on the reef flat (Fig. 3). $H$. chloropterus and Labrichthys unilineatus were found on reef flats and crests or shallow parts of the reef slope on both sides of the reef. Diproctacanthus xanthurus, $H$. purpurescens, Oxycheilinus celebicus and Paracheilinus filamentosus were only found on reef slopes and walls, both on the front and back of reefs. The remaining 3 species (H. melanurus, Labroides dimidiatus and Thalassoma lunare) were apparent reef zone generalists, occupying most of the available reef zones (Fig. 3).

Halichoeres melanurus, $H$. purpurescens and Oxycheilinus celebicus were very general in their use of microhabitats, utilising most of the microhabitat categories in this study (Table 2). Thalassoma lunare and Labroides dimidiatus were found in most micro-

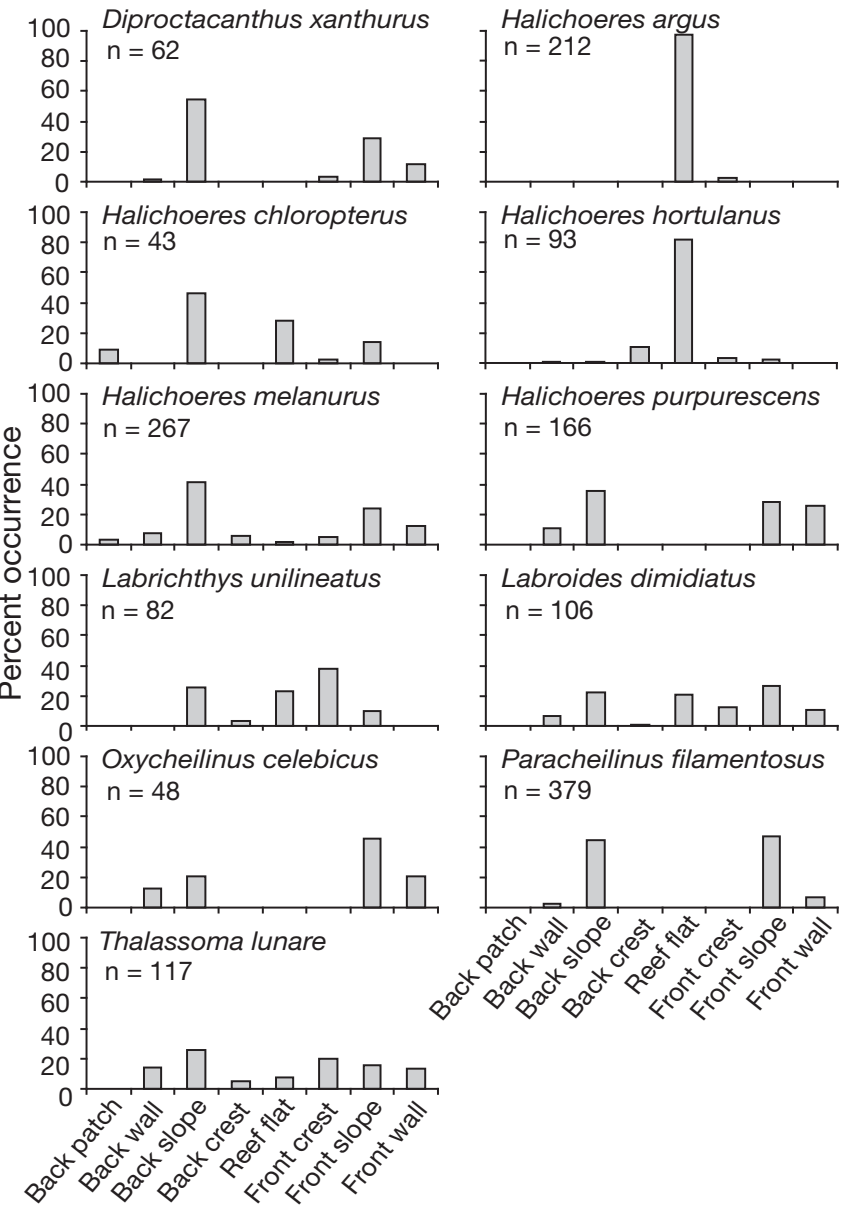

Fig. 3. Local horizontal distributions of 11 species of juvenile wrasses on coral reefs in Kimbe Bay, Papua New Guinea, shown as the percent occurrence of individuals in each of the 8 reef zones 
habitats but more than $70 \%$ of the individuals were associated with live hard corals. Diproctacanthus xanthurus and Labrichthys unilineatus were found almost exclusively on live hard coral (over 95\%). Paracheilinus filamentosus was most commonly found associated with rubble on reef slopes and walls. $H$. chloropterus was mainly found on dead substrata, mostly rubble (and turf). H. argus was associated with turf-covered dead coral/rubble, while $H$. hortulanus was found in sand, rubble gutters along the reef crest, shallow slope or reef flat (Table 2). For 7 species $(O$. celebicus, D. xanthurus, $H$. melanurus, H. purpurescens, Labroides dimidiatus, Labrichthys unilineatus, T. lunare), over $55 \%$ of the individuals occupied live coral. All of these species, except Labrichthys unilineatus, were very general in their use of live corals. Labrichthys unilineatus was mostly associated with bushy or branching corals from the families Acroporidae and Pocilloporidae (Table 2).

\section{Diet}

Most juvenile wrasses showed a high selectivity for harpacticoid copepods; however, the importance of harpacticoids in the diet differed among species. Calanoid copepods were the dominant prey items of Halichoeres purpurescens and Paracheilinus filamentosus, constituting 32 and $23 \%$ of their diet content, respectively (Table 3). Labrichthys unilineatus fed exclusively on live coral. Labroides dimidiatus showed high selectivity for parasitic gnathid isopod larvae, which constituted over $90 \%$ of their diet. Diproctacanthus xanthurus was also highly selective on parasites, gnathid isopod larvae as well as copepods, which constituted 59 and $24 \%$ of the diet content, respectively (Table 3 ).

\section{Niche breadths}

In general, niche values covered the whole spectrum from highly specialised diets and microhabitat use to quite gener-

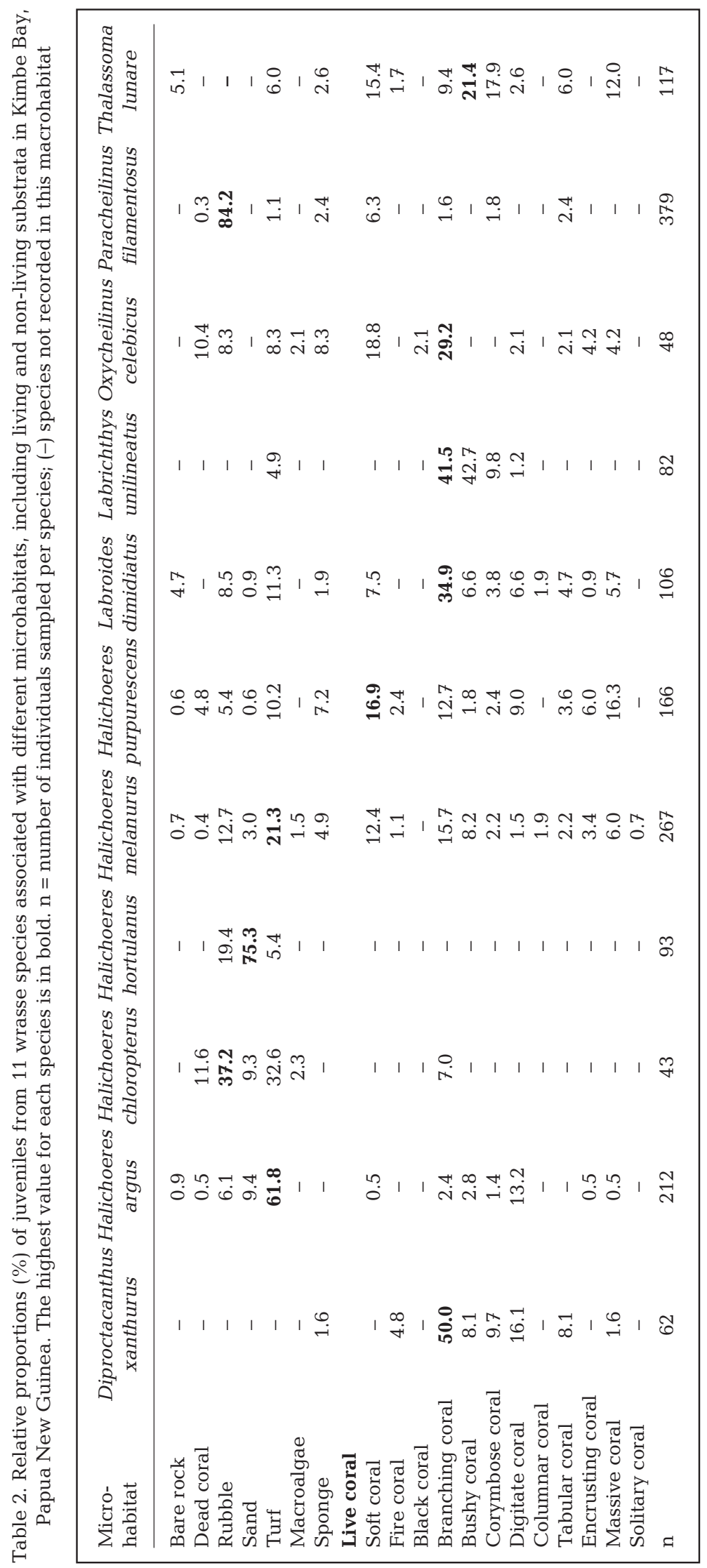




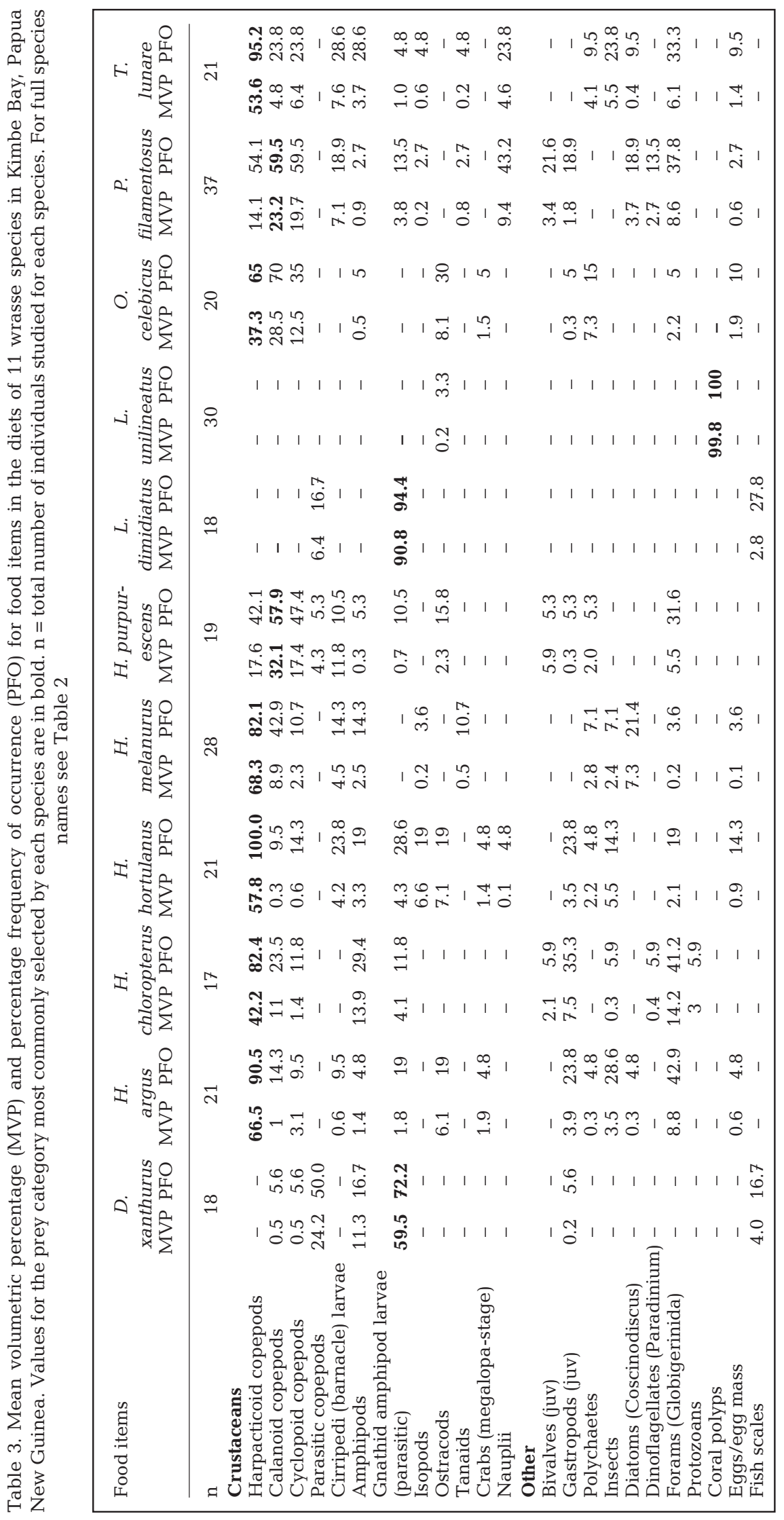

alised with regard to macrohabitat use (depth ranges and reef zones occupied). No species was either a specialist or a generalist in its use of all resources. In terms of both microhabitat use and diet, species displayed niche values at the lower end of the spectrum, indicating a general trend of specialisation in these resources by juvenile wrasses. Halichoeres purpurescens, $H$. melanurus and Thalassoma lunare were the most general of all species in the use of microhabitats, but the highest niche breadth value among these species was only 0.5 (Table 4). The narrowest niche breadths with regard to diet were displayed by Labrichthys unilineatus, Labroides dimidiatus and $H$. melanurus, while Paracheilinus filamentosus had the highest niche breadth value of 0.3 (Table 4 ).

\section{Local abundance and niche breadth}

Halichoeres melanurus was the most abundant species, followed by Thalassoma lunare and $H$. purpurescens (Fig. 4). The remaining species were all relatively rare, i.e. $\leq 1$ individual per $100 \mathrm{~m}^{2}$ (Fig. 4). There was a significant positive relationship between niche breadth for microhabitat and local abundance $\left(r^{2}=0.606, p=0.005\right)$. The most abundant species were among those with the greatest niche breadths for microhabitat (i.e. $H$. melanurus, T. lunare and $H$. purpurescens). There were no relationships between the other 3 niche dimensions (depth, reef zone or diet) and abundance.

\section{Local distribution and niche breadth}

Halichoeres melanurus had the broadest distribution across reef 
Table 4. Niche values for different niche dimensions (depth, reef zone, microhabitat and diet) of 11 species of juvenile wrasses in Kimbe Bay, Papua New Guinea. A low niche value represents a narrow niche breadth and high specialisation. Likewise, a high value represents a wide niche breadth and low specialisation. $\mathrm{n}=$ number of categories within each niche dimension

\begin{tabular}{|lcccc|}
\hline Species & $\begin{array}{c}\text { Depth } \\
(\mathrm{n}=8)\end{array}$ & $\begin{array}{c}\text { Reef zone } \\
(\mathrm{n}=8)\end{array}$ & $\begin{array}{c}\text { Microhabitat } \\
(\mathrm{n}=19)\end{array}$ & $\begin{array}{c}\text { Diet } \\
(\mathrm{n}=23)\end{array}$ \\
\hline Diproctacanthus xanthurus & 0.69 & 0.22 & 0.13 & 0.06 \\
Halichoeres argus & 0.00 & 0.01 & 0.08 & 0.05 \\
Halichoeres chloropterus & 0.17 & 0.30 & 0.15 & 0.15 \\
Halichoeres hortulanus & 0.01 & 0.07 & 0.04 & 0.08 \\
Halichoeres melanurus & 0.38 & 0.42 & 0.41 & 0.05 \\
Halichoeres purpurescens & 0.81 & 0.36 & 0.47 & 0.20 \\
Labroides dimidiatus & 0.39 & 0.59 & 0.28 & 0.01 \\
Labrichthys unilineatus & 0.09 & 0.38 & 0.10 & 0.00 \\
Oxycheilinus celebicus & 0.62 & 0.31 & 0.30 & 0.14 \\
Paracheilinus filamentosus & 0.54 & 0.20 & 0.02 & 0.28 \\
Thalassoma lunare & 0.22 & 0.69 & 0.35 & 0.10 \\
\hline
\end{tabular}

zones, occupying all 8 reef zones, while $H$. argus displayed the narrowest distribution, occupying just 2 reef zones (Fig. 5). No relationships were found between any of the 3 niche values (depth, microhabitat or diet) and local horizontal distribution, i.e. across reef zones. However, there was a significant positive relationship between microhabitat niche breadth and local vertical distribution, i.e. among depth zones $\left(r^{2}=0.433, p=0.028\right)$. The species with the highest microhabitat niche value had the broadest local vertical distribution (H. purpurescens), and the species with the lowest microhabitat niche values had the narrowest vertical distributions ( $H$. argus, $H$. hortulanus, H. chloropterus and Labrichthys unilineatus).

\section{Geographic range and niche breadth}

Thalassoma lunare had the largest geographic range, closely followed by Halichoeres hortulanus (Fig. 5). H. purpurescens and Paracheilinus filamentosus had the smallest ranges of the 11 species, with range sizes roughly a third of that of Thalassoma lunare (Fig. 5). There were no relationships between niche values (depth, reef zones, microhabitats or diet) and geographic range. $H$. purpurescens was the most generalised species in all 4 niche dimensions, but it had the most restricted geographic range. In contrast, $H$. hortulanus, which is an apparent depth specialist, had the second widest geographic range.

\section{Local abundance and geographic range}

There was no relationship found between local abundance and geographic range in the 11 labrid species examined $\left(r^{2}=0.045, p=0.533\right)$. Species with wide geographic ranges did not seem to have high local abundances in this study.

\section{DISCUSSION}

The results from this study suggest that ecological versatility in fishes from the family Labridae in Kimbe Bay, Papua New Guinea, plays an important role in the distribution and abundance of species on a local scale. A broad use of microhabitats was associated with high local abundances and broad local depth distributions, suggesting that the degree of specialisation on a microhabitat-level may well restrict the abundance and distribution of juvenile wrasses. However, no relationship was found between local abundance and distribution. In addition, on a larger (geographic) scale, ecological versatility does not appear to be important for limiting the distribution of species.

The results of this study provide limited support for Brown's (1984) hypothesis linking specialisation and abundance. We found that use of a broad range of microhabitats was associated with high local abundances and broad depth distributions. On the other hand, no other relationship between niche breadth and local distribution and abundance was found for the remaining resources. On a larger scale, no associations between either niche breadth or local abun-

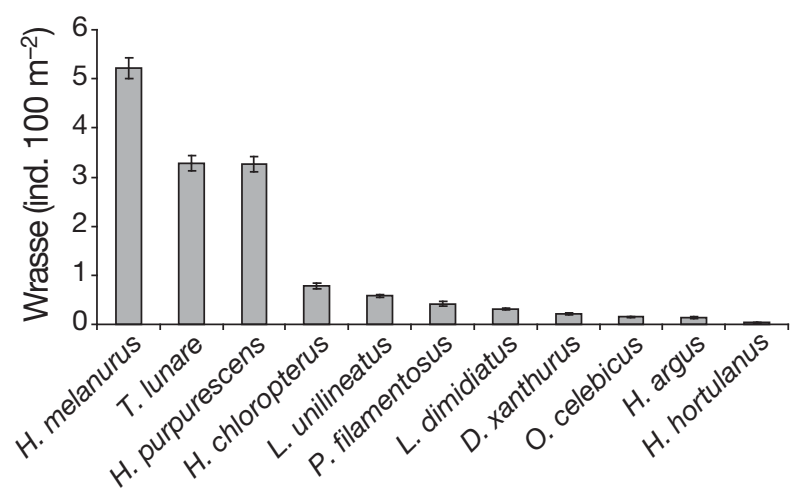

Fig. 4. Mean densities of 11 species of juvenile wrasses on coral reefs in Kimbe Bay, Papua New Guinea. Error bars are \pm 1 SE. For full species names see Fig. 2 

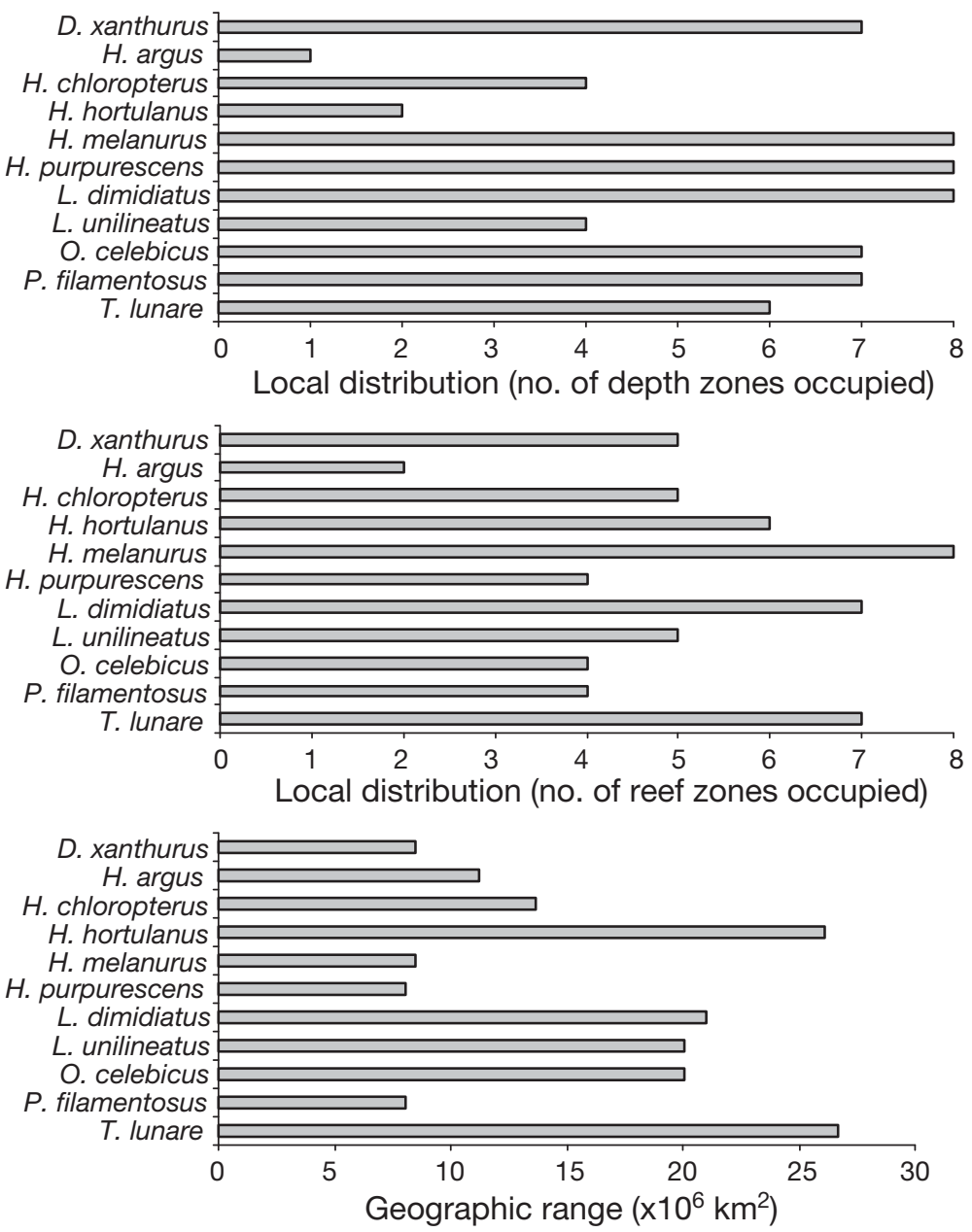

Fig. 5. Local and geographic distributions for 11 species of juvenile wrasses in Kimbe Bay, Papua New Guinea. Local distribution expressed as vertical (no. of depth zones) and horizontal (no. of reef zones) distribution. Geographic distribution expressed as geographic range $\left(\mathrm{km}^{2}\right)$. For full species names see Fig. 2

dance and geographic range were detected. The local patterns are consistent with previous studies in Kimbe Bay, Papua New Guinea, on coral dwelling gobies (Munday 2000), triggerfish (Bean et al. 2002) and cardinalfish (Gardiner \& Jones 2005), all of which found that the most specialised species had the lowest local abundances. Microhabitat specialisation was also found to restrict the depth distribution among a group of triggerfish (Bean et al. 2002).

Many of the niche parameters measured, including habitat zone, depth and microhabitat, are likely to co-vary. Hence, further work is required to identify the specific resources limiting abundance. Given that microhabitat availability is known to change with depth, experimental studies are required to distinguish the roles of microhabitat and depth per se on local abundance (e.g. Srinivasan 2003). Also, this study focused on juveniles, and given that versatility may change with ontogeny, the applicability of our results to adult fishes requires further investigation.

According to Brown's (1984) hypothesis, the low local abundance and narrow distribution displayed by many taxa can be explained by high resource specialisation. Specialists are expected to have lower local abundances and limited distributions because the extent of suitable resources is likely to be more restricted for specialised species than for species that can use a variety of resources. Halichoeres hortulanus appeared to be the most specialised species in terms of microhabitat and was also found to be the least abundant species with a restricted depth range in our study, suggesting that this species' local abundance and distribution might be limited by the restricted number of microhabitats available on the reef. $H$. hortulanus was always found in sand or rubble gutters in shallow water, and its abundance and distribution are likely to be restricted by the availability of its preferred microhabitat. The 3 most abundant species in our study (H. melanurus, Thalassoma lunare and $H$. purpurescens) were the most generalised in terms of microhabitat usage. They also displayed the broadest depth distributions. Being a microhabitat generalist most likely allows a species to access and move among a broader range of resources in other niche dimensions than a microhabitat specialist would, hence enabling it to achieve higher local abundance. However, if a species specialises on the most abundant resources, then specialisation and low abundance need not be associated (Jones et al. 2002). For example, the anemonefish Premnas biaculeatus on the Great Barrier Reef, Australia, and on coral reefs of Papua New Guinea is a habitat specialist but is still the most abundant species of anemonefish in these regions (Fautin \& Allen 1992).

According to Brown (1984), species-abundance distributions and species-range distributions should have the same mechanistic basis, i.e. both should be dependent on the versatility displayed by a particular species. Gaston (1996) suggested that species-rangesize distributions are simply species-abundance distributions on a larger scale. Species with narrow habitat requirements might have difficulty in colonis- 
ing new areas and hence have a limited range. Geographic range was correlated with niche breadth in a number of terrestrial studies (Gaston 1988, e.g. Inkinen 1994, Pyron 1999, Hughes 2000), but not in the present study. Instead, contrary to predictions, there was no relationship between niche breadth and geographic range for any of the resources, i.e. resource specialisation does not limit the geographic range of these species. Similar results were found by Jones et al. (2002) for 2 groups of coral reef fishes, anemonefishes and butterflyfishes. There is, however, some support for the specialisation/geographic range relationship in coral reef fishes from a study by Hawkins et al. (2000), where depth, habitat and distribution data on coral reef fish were compiled from a number of sources. Hawkins et al. (2000) showed that there was a trend for restricted-range species to have narrower depth ranges; however, only $57 \%$ of restricted-range species had high levels of microhabitat selectivity.

The results from the present study suggest that the geographic ranges of coral reef fishes are not limited by the level of ecological versatility. Although specialised coral reef fish are most often locally rare, high levels of specificity do not necessarily result in narrow geographic ranges. Factors other than niche specialisation appear to be of greater importance in restricting geographic distributions. For example, the dispersal and establishment abilities of a species can strongly influence its geographic range. It has been suggested that factors such as dispersal characteristics may be more influential as spatial scale increases (Palmer et al. 1996). The time larvae spend in the plankton stage varies between species (Victor 1986, Cowen 1991, Leis 1991) and may have a profound effect on species geographic range. However, other factors including competition, predation, climatic/ environmental tolerances and historical events have also been suggested to limit the distribution of species (Gaston 1996), and should not be ignored in models predicting patterns of distribution in coral reef fish.

It has been suggested that resource specialists may be more prone to rapid decline and extinction than generalists, due to their inability to switch resources when preferred resources become scarce (Jones et al. 2002). Several studies have found that the abundance of coral dwelling fishes rapidly declined when corals they inhabited declined in numbers (BouchonNavaro et al. 1985, e.g. Munday et al. 1997, Munday 2004). Munday (2004) also found that specialists suffered proportionately greater losses in abundance than generalists when coral habitat declined. Most juvenile wrasses in our study displayed some level of microhabitat specialisation. Furthermore, we found a positive relationship between microhabitat specialisation and abundance, suggesting that the most specialised species are likely to be at risk if their preferred habitats decline.

More than half of the species were predominantly associated with live coral, particularly branching and bushy hard corals. Juvenile fish are often found associated with live branching corals, as these provide shelter and protection from predators (Öhman \& Rajasuriya 1998, Öhman et al. 1998). Branching corals are more sensitive to disturbances such as storms and coral bleaching than corals of other growth forms (Woodley et al. 1981, Hughes \& Connell 1999) and hence many of the labrid species in this study may be at risk if such disturbances increase as predicted. Major changes are occurring on coral reefs around the world, and $50 \%$ of the remaining coral reefs are in decline (Wilkinson 2004). On several inshore reefs in Kimbe Bay, there was a gradual decline in branching coral cover from 1997 to 2001 (Jones et al. 2004). Recent studies have highlighted the effect of degraded coral reefs on fish communities, and particularly fish species that are dependent on live coral for food or habitat are negatively affected (Jones et al. 2004, Wilson et al. 2006, Pratchett et al. 2008, Wilson et al. 2009).

Many of the juvenile wrasses in this study also displayed high dependency on a single food item (harpacticoid copepods). Clearly, these species are potentially at risk should degradation of reefs extend to this resource. While loss of coral may have little impact on planktonic food, the effects of coastal runoff and ocean warming on the food-base requires further investigation.

In conclusion, this study provides support for the hypothesis that ecological versatility in juvenile wrasses can have implications for the abundance and distribution on a local scale. However, contrary to Brown's hypothesis, we found no relationship between ecological versatility and geographic range or between species abundance and distribution. Species are not versatile in all resources at once, and hence a relationship between versatility and abundance/distribution is dependent on which resource is being investigated. For many reef fishes, high levels of habitat specialisation may well restrict local abundances, but levels of specialisation are unlikely to limit geographic distributions. Other factors that are likely to be important for limiting geographic distributions in these communities, such as relative dispersal ability, require further investigation. 
Acknowledgements. Many thanks to J. Larsson, L. Gamfeldt, J. Harris, S. Kistle, J. Loga, W. D. Robbins, M. Schläppy and dive staff at Walindi Plantation Resort for their assistance with field work and the residents of Kilu and Tamare villages near Walindi for allowing access to their reefs. Thank you C.G. Alexander for your guidance and advice during gut content analysis. This research was supported by: Mahonia Na Dari Research and Conservation Centre; Walindi Plantation Resort; the School of Marine and Tropical Biology, James Cook University; an International Postgraduate Research Scholarship and a JCU Postgraduate Scholarship to M.S.; and an Australian Research Council Discovery Grant to G.P.J. The present study is in compliance with the current laws of Papua New Guinea.

\section{LITERATURE CITED}

Allen GR, Steene R, Allen M (1998) A guide to angelfishes and butterflyfishes. Odyssey Publishing, Perth

Allen GR, Steene R, Humann P, DeLoach N (2003) Reef fish identification: Tropical Pacific. New World Publications, Jacksonville, FL

Bean K, Jones GP, Caley MJ (2002) Relationships among distribution, abundance and microhabitat specialisation in a guild of coral reef triggerfish (family Balistidae). Mar Ecol Prog Ser 233:263-272

> Bock CE, Ricklefs RE (1983) Range size and local abundance of some North American songbirds: a positive correlation. Am Nat 122:295-299

Bonin MC, Almany GR, Jones GP (2011) Contrasting effects of habitat loss and fragmentation on coral-associated reef fishes. Ecology 92:1503-1512

Bouchon-Navaro Y, Bouchon C, Harmelin-Vivien ML (1985) Impact of coral degradation on a chaetodontid fish assemblage (Moorea, French Polynesia). Proc 5th Int Coral Reef Congr, Tahiti 5:427-432

> Brown JH (1984) On the relationship between abundance and distribution of species. Am Nat 124:255-279

Cowen RK (1991) Variation in the planktonic larval duration of the temperate wrasse Semicossyphus pulcher. Mar Ecol Prog Ser 69:9-15

> Davies KF, Margules CR, Lawrence JF (2004) A synergistic effect puts rare, specialized species at greater risk of extinction. Ecology 85:265-271

$>$ DeMartini EE, Friedlander AM (2004) Spatial patterns of endemism in shallow-water reef fish populations of the Northwestern Hawaiian Islands. Mar Ecol Prog Ser 271: 281-296

Fautin DG, Allen GR (1992) Field guide to anemonefishes and their host sea anemones. Western Australian Museum, Perth

Fowler SV, Lawton JH (1982) The effects of host-plant distribution and local abundance on the species richness of agromyzid flies attacking British umbellifers. Ecol Entomol 7:257-265

Froese R, Pauly D (2002) Fishbase. www.fishbase.org (accessed 20 January 2002)

Futuyma DJ, Moreno G (1988) The evolution of ecological specialisation. Annu Rev Ecol Syst 19:207-233

> Gardiner NM, Jones GP (2005) Habitat specialisation and overlap in a guild of coral reef cardinalfishes (Apogonidae). Mar Ecol Prog Ser 305:163-175

Gaston KJ (1988) Patterns in the local and regional dynamics of moth populations. Oikos 53:49-57
Gaston KJ (1990) Patterns in the geographical ranges of species. Biol Rev Camb Philos Soc 65:105-129

Gaston KJ (1994) Rarity. Chapman \& Hall, London

> Gaston KJ (1996) Species-range-size distributions: patterns mechanisms and implications. Trends Ecol Evol 11: 197-201

> Gaston KJ, Blackburn TM (1996) Global scale macroecology: interactions between population size, geographic range size and body size in the Anseriformes. J Anim Ecol 65:701-714

Gaston KJ, Spicer JI (2001) The relationship between range size and niche breadth: a test using five species of Gammarus (Amphipoda). Glob Ecol Biogeogr 10:179-188

> Gaston KJ, Blackburn TM, Lawton JH (1997) Interspecific abundance-range size relationships: an appraisal of mechanisms. J Anim Ecol 66:579-601

> Graham N (2007) Ecological versatility and the decline of coral feeding fishes following climate driven coral mortality. Mar Biol 153:119-127

> Green AL (1996) Spatial, temporal and ontogenetic patterns of habitat use by coral reef fishes (Family Labridae). Mar Ecol Prog Ser 133:1-11

> Gregory RD, Gaston KJ (2000) Explanations of commonness and rarity in British breeding birds: separating resource use and resource availability. Oikos 88:515-526

Hanski I (1982) Dynamics of regional distribution; the core and satellite species hypothesis. Oikos 38:210-221

> Hanski I, Gyllenberg M (1997) Uniting two general patterns in the distribution of species. Science 275:397-400

Hanski I, Kouki J, Halkka A (1993) Three explanations of the positive relationship between distribution and abundance of species. In: Ricklefs RE, Schluter D (eds) Species diversity in ecological communities. University of Chicago Press, Chicago, IL, p 108-116

Harcourt AH, Coppeto SA, Parks SA (2002) Rarity, specialization and extinction in primates. J Biogeogr 29:445-456

> Hawkins JP, Roberts CM, Clark V (2000) The threatened status of restricted-range coral reef fish species. Anim Conserv 3:81-88

Hobbs JP, Jones G, Munday P (2010) Rarity and extinction risk in coral reef angelfishes on isolated islands: interrelationships among abundance, geographic range size and specialisation. Coral Reefs 29:1-11

Hobbs JPA, Jones GP, Munday PL (2011) Extinction risk in endemic marine fishes. Conserv Biol 25:1053-1055

Hughes JB (2000) The scale of resource specialization and the distribution and abundance of lycaenid butterflies. Oecologia 123:375-383

Hughes TP, Connell JH (1999) Multiple stressors on coral reefs: a long-term perspective. Limnol Oceanogr 44: 932-940

> Hurlbert SH (1978) The measurement of niche overlap and some relatives. Ecology 59:67-77

Inkinen P (1994) Distribution and abundance in British noctuid moths. Ann Zool Fenn 31:235-243

Jones GP, Caley MJ, Munday PL (2002) Rarity in coral reef fish communities. In: Sale PF (ed) Coral reef fishes: dynamics and diversity in complex ecosystems. Academic Press, New York, NY, p 81-101

> Jones GP, McCormick MI, Srinivasan M, Eagle JV (2004) Coral decline threatens fish biodiversity in marine reserves. Proc Natl Acad Sci USA 101:8251-8253

Krebs GJ (ed) (1999) Niche measures and resource preferences. In: Ecological methodology. Addison-Welsey Educational Publishers, Menlo Park, CA, p 455-495 
Leis JM (1991) The pelagic stage of reef fishes: the larval biology of coral reef fishes. In: Sale PF (ed) The ecology of fishes on coral reefs. Academic Press, San Diego, CA, p $183-230$

Levins R (1968) Evolution in changing environments: some theoretical explorations, Vol 2. Princeton University Press, Princeton, NJ

Liem KF (1984) Functional versatility, speciation, and niche overlap: Are fishes different? In: Meyers DG, Strickler JR (eds) Trophic interactions within aquatic ecosystems. Westview Press, Boulder, CO, p 269-305

Liem KF (1990) Aquatic versus terrestrial feeding modes: possible impacts on the trophic ecology of vertebrates. Am Zool 30:209-221

MacNally RC (1995) Ecological versatility and community ecology. Cambridge University Press, Melbourne

Manly BFJ, McDonald LL, Thomas DL (1993) Resource selection by animals. Chapman \& Hall, London

McNaughton SJ, Wolf LL (1970) Dominance and the niche in ecological systems. Science 167:131-139

McPeek MA (1996) Trade-offs, food web structure, and the coexistence of habitat specialists and generalists. Am Nat 148:S124-S138

Morris DW (1996) Coexistence of specialist and generalist rodents via habitat selection. Ecology 77:2352-2364

Munday PL (2000) Interactions between habitat use and patterns of abundance in coral-dwelling fishes of the genus Gobiodon. Environ Biol Fishes 58:355-369

Munday PL (2002) Does habitat availability determine geographical-scale abundances of coral-dwelling fishes? Coral Reefs 21:105-116

Munday PL (2004) Habitat loss, resource specialization, and extinction on coral reefs. Glob Change Biol 10: 1642-1647

Munday PL, Jones GP (1998) The ecological implications of small body size among coral-reef fishes. Oceanogr Mar Biol Annu Rev 36:373-411

> Munday PL, Jones GP, Caley MJ (1997) Habitat specialisation and the distribution and abundance of coraldwelling gobies. Mar Ecol Prog Ser 152:227-239

Myers RF (1999) Micronesian reef fishes: a comprehensive guide to the coral reef fishes of Micronesia. Coral Graphics, Guam

Öhman MC, Rajasuriya A (1998) Relationships between habitat structure and fish communities on coral and sandstone reefs. Environ Biol Fishes 53:19-31

Öhman MC, Munday PL, Jones GP, Caley MJ (1998) Settlement strategies and distribution patterns of coral-reef fishes. J Exp Mar Biol Ecol 225:219-238

Palmer MA, Allan JD, Butman CA (1996) Dispersal as a regional process affecting the local dynamics of marine and stream benthic invertebrates. Trends Ecol Evol 11: 322-326

Pianka ER (1974) The ecological niche. In: Pianka ER (ed)

Editorial responsibility: Charles Birkeland,

Honolulu, Hawaii, USA
Evolutionary ecology. Harper \& Row, New York, NY, p 267-293

Pratchett M (2005) Dietary overlap among coral-feeding butterflyfishes (Chaetodontidae) at Lizard Island, northern Great Barrier Reef. Mar Biol 148:373-382

Pratchett MS, Wilson SK, Baird AH (2006) Declines in the abundance of Chaetodon butterflyfishes following extensive coral depletion. J Fish Biol 69:1269-1280

Pratchett MS, Munday PL, Wilson SK, Graham NAJ and others (2008) Effects of climate-induced coral bleaching on coral-reef fishes-ecological and economic consequences. Oceanogr Mar Biol Annu Rev 46:251-296

> Pyron M (1999) Relationships between geographical range size, body size, local abundance, and habitat breadth in North American suckers and sunfishes. J Biogeogr 26: 549-558

Rachlin JW, Warkentine BE, Pappantoniou A (1989) The use of niche breadth and proportional similarity in feeding to stipulate resource utilization strategies in fish. J Fish Biol 5:103-112

Randall JE, Allen GR, Steene RC (1997) The complete divers' $\&$ fishermen's guide to fishes of the Great Barrier Reef and Coral Sea. Crawford House Publishing, Bathurst, p 557

Ross ST (1986) Resource partitioning in fish assemblages: a review on field studies. Copeia 1986:352-388

Schoener TW (1974) Resource partitioning in ecological communities. Science 185:27-39

Srinivasan M (2003) Depth distributions of coral reef fishes: the influence of microhabitat structure, settlement, and post-settlement processes. Oecologia 137:76-84

Srinivasan M, Jones G (2006) Extended breeding and recruitment periods of fishes on a low latitude coral reef. Coral Reefs 25:673-682

Thresher RE (1991) Geographic variability in the ecology of coral reef fishes: evidence, evolution, and possible implications. In: Sale PF (ed) The ecology of fishes on coral reefs. Academic Press, Sydney, p 401-436

Timms R, Read AF (1999) What makes a specialist special? Trends Ecol Evol 14:333-334

- Victor BC (1986) Duration of the planktonic larval stage of one hundred species of Pacific and Atlantic wrasses (family Labridae). Mar Biol 90:317-326

Wilkinson C (2004) Status of coral reefs of the world: 2004. Australian Institute of Marine Sciences, Townsville

Wilson SK, Graham NAJ, Pratchett MS, Jones AG, Polunin NVC (2006) Multiple disturbances and the global degradation of coral reefs: are reef fishes at risk or resilient? Glob Change Biol 12:2220-2234

Wilson S, Dolman A, Cheal A, Emslie M, Pratchett M, Sweatman H (2009) Maintenance of fish diversity on disturbed coral reefs. Coral Reefs 28:3-14

Woodley JD, Chornesky EA, Clifford PA, Jackson JBC and others (1981) Hurricane Allen's impact on Jamaican coral reefs. Science 214:749-755

Submitted: November 16, 2011; Accepted: April 26, 2012

Proofs received from author(s): Augsust 3, 2012 